\title{
Melhoria de Processo de Teste Brasileiro (MPT.BR)
}

\author{
Ivaldir H. de Farias Junior ${ }^{1,2}$ \\ ${ }^{1}$ UPE, Universidade de Pernambuco - Recife - PE \\ ${ }^{2}$ Softex Recife - Recife - PE \\ ivaldir.fariasdupe.br, juniordrecife.softex.br
}

Resumo. Atualmente podemos perceber a intensa busca das organizações de TI e, mais especificamente as empresas de desenvolvimento de software por melhorias em seus produtos. A ausência de um processo definido de teste de software vem trazendo grandes prejuízos para essas organizações. Incentivado por este contexto, foi concebido o modelo MPT.Br que é baseado nas melhores práticas de teste de software do mercado. Esse modelo promove a integração das atividades de engenharia de software, otimizando os processos de teste para alcançar os resultados desejados através da entrega de produtos com qualidade. $\mathrm{O}$ principal objetivo desta palestra é prover para os participantes uma visão geral do modelo que trata da melhoria do processo de teste de software através de melhores práticas, tendo como principais benefícios: abordar a melhoria contínua nos processos de teste conforme os objetivos organizacionais e nível de maturidade almejado; fornecer uma base para avaliação e consequente identificação do grau de maturidade presente nas organizações; e reunir as melhores práticas e estruturá-las segundo o grau de complexidade versus o nível de maturidade que a mesma estará relacionada. 